\title{
Planos locais de promoção da saúde: intersetorialidade(s) construída(s) no território
}

\author{
Local health promotion plans: intersetoralities \\ created in the territory
}

Simone Tetu Moysés ${ }^{1}$ Ronice Franco de Sá ${ }^{2}$
${ }^{1}$ Escola de Saúde e Biociências, Pontifícia Universidade Católica do Paraná. R. Imaculada Conceição 1155, Prado Velho. 81611-970 Curitiba PR Brasil. simone.moyses@pucpr.br ${ }^{2}$ Núcleo de Saúde Pública e Desenvolvimento Social, Universidade Federal de Pernambuco.

\begin{abstract}
The article highlights the importance of considering the specificities of spaces/territories/ locations of individual and collective life in creating health promotion actions. It explores how this approach has conceptually consolidated respect for territoriality and territorial actions as a principle and an operational health promotion strategy. Based on the literature, the article also points to the need to envision the territory occupied as a locus to put intersetorialities into practice, giving a voice to people who live there, seek to and solve their complex problems, to existing and emerging social networks. It also presents a nationally and internationally validated strategy/ method (Bamboo Method) for the development of local health promotion plans, which enables the prioritization of actions by listening to the people and to the managers.
\end{abstract}

Key words Health promotion, Territory, Healthy city, Autonomy
Resumo O artigo aponta para a importância de se considerar as especificidades dos espaços/ territórios/locais de vida individual e coletiva na construção de ações de promoção da saúde e explora como essa abordagem tem consolidado conceitualmente o respeito às territorialidades e à territorialização das ações como um princípio e uma estratégia operacional da promoção da saúde. Com base na literatura selecionada, os autores discutem a necessidade de se vislumbrar o território vivido enquanto locus para operacionalizar intersetorialidade(s), dando voz às pessoas que ali vivem, desejam e resolvem seus problemas complexos, às redes sociais já existentes e àquelas emergentes. Apresentam ainda uma estratégial método validado (Método Bambu) nacional e internacionalmente para elaboração de planos locais de promoção da saúde, o qual permite a priorização de ações mediante a escuta da população e dos gestores.

Palavras-chave Promoção da saúde, Território, Município saudável, Autonomia 


\section{Introdução}

Iniciativas de promoção da saúde caracterizamse por sua concepção holística, pela intersetorialidade, favorecimento do empoderamento comunitário e da participação social, pela busca da equidade por meio da ação sobre os determinantes sociais da saúde, e pelo desenvolvimento de ações multiestratégicas e sustentáveis ${ }^{1}$. Sua efetividade é, portanto, fortemente dependente do contexto, definido como "as circunstâncias que formam o ambiente no qual as ações acontecem". São esses "ambientes nos quais as ações acontecem", que constituem os locais/espaços/ territórios do fazer e viver cotidiano que precisam ser priorizados na busca das soluções complexas para as questões afeitas às iniquidades sociais que o campo da promoção da saúde se propõe enfrentar.

A importância do desenvolvimento de planos locais para a efetivação de ações promotoras de saúde com foco na construção de ambientes e territórios saudáveis tem sido reconhecida, desde a década de 1980, como um eixo transversal de políticas intersetoriais baseadas na concepção ampliada de saúde e centradas na dinâmica de sua produção social ${ }^{3}$. Entretanto, o desenvolvimento de políticas públicas com este enfoque de base territorial/local ainda é considerado um desafio no contexto brasileiro, o que tem comprometido significativamente tanto sua adequação às realidades locais como seu impacto no combate às iniquidades e garantia do direito à saúde ${ }^{4}$. Portanto, é importante consolidar o reconhecimento de territorialidades como um princípio e a territorialização como uma estratégia operacional na construção de práticas de promoção da saúde.

\section{Entendendo sobre espaço, território e territorialidades}

Discutir planos locais territorializados implica em conhecer as peculiaridades de cada espaço/território. Elaborar esses planos e promover saúde e desenvolvimento local alicerçados em concepções e ações intersetoriais também exige alinhar conceitos e conhecimento sobre espaço, território e territorialidades.

Para o francês Lefevbre ${ }^{5}$ o espaço pode ser compreendido a partir da inter-relação de três dimensões: o espaço percebido, associado à perspectiva física, à prática onde a sociedade associa a realidade cotidiana e a realidade espacial construída; o espaço concebido, que corresponde às representações onde acontecem as práticas sociais e políticas; e o espaço vivido, espaço de representações sociais do cotidiano, das situações vividas pelas pessoas e coletividades. Para Lefevbre o espaço vivido não deveria ser penalizado em prol do espaço concebido. Por isso, é preciso dar voz aos sujeitos e às suas vivências no local.

Avançando na discussão sobre espaço e território, pesquisadores brasileiros como Haesbaer ${ }^{6}$ entendem que território é um conceito mais abrangente que aquele de espaço. Há múltiplas abordagens sobre as concepções de território e, por conseguinte, um grande número de enfoques. No entanto, independente da acepção, há uma concordância em que o conceito de território está atrelado à constatação da existência de poder no espaço: poder jurídico-político, cultural (dimensão simbólica), econômico. O território é, assim, o local onde se manifesta o poder nas suas variadas formas. Nesse caso, o poder que considera as subjetividades, o imaginário e a identidade/pertencimento ao local é, sem dúvida, o poder simbólico. É o poder que permite a apropriação horizontal do espaço. Para Raffestin ${ }^{7}$ o território se forma a partir do espaço, é o resultado de uma ação conduzida por um ator em qualquer nível. Ao se apropriar de um espaço, concreta ou abstratamente, $\mathrm{o}$ ator "territorializa" o espaço.

O conceito de território em uso, ou território vivo, proposto por Santos ${ }^{8}$, aponta também importantes aspectos a serem considerados na construção de ações de promoção da saúde territorializadas. Trata-se de ampliar a compreensão das relações humanas com o espaço local ocupado, sua complexidade e historicidade definidos na interação tempo-espaço. A produção social do contexto local está, desta forma, intimamente relacionada ao cotidiano da população e às relações sociais dinâmicas, muitas vezes influenciadas por relações de poder de dominação e apropriação deste espaço. Assim, princípios e valores da promoção da saúde ligados, por exemplo, ao empoderamento comunitário e ao favorecimento da participação, bem como o desenvolvimento de ações intersetoriais focadas na equidade, devem ser contextualizados na dinamicidade das relações vividas no espaço local.

Já as territorialidades são a "razão de ser" dos territórios, conferindo-lhes existência, seja material ou imaterial. Segundo Raffestin ${ }^{7}$, a territorialidade é composta por três elementos: senso de identidade espacial; senso de exclusividade; e compartimentação da interação humana no espaço. Sua função é a manutenção do território, ou seja, sua defesa, garantindo equilíbrio entre as sociedades e a natureza. 
A construção de políticas públicas e planos locais de saúde a partir do olhar sobre o território no contexto brasileiro tem sido apontada como um desafio a ser enfrentado. De acordo com Araú$\mathrm{jo}^{9}$, diferentes abordagens de territorialização no campo das políticas públicas, em especial naquelas de proteção social, podem ser exemplificadas no Brasil, entre elas "políticas territorializadas baseadas na articulação entre as esferas nacional, estadual e municipal, como no caso do Sistema Único de Saúde; programas e ações construídas a partir de bases territoriais específicas, como políticas voltadas para áreas rurais; construção de planos territoriais específicos como espaços próprios de planejamento da ação governamental; além de políticas territoriais propriamente ditas, privilegiando um enfoque de desenvolvimento endógeno ou em movimento bottom-up".

De qualquer modo, considera-se que a construção de políticas e planos de ação locais podem oportunizar a democratização das relações entre os diversos atores, otimizar acesso aos direitos sociais, além de reduzir iniquidades socioterritoriais, sem excluir singularidades e diversidades locais. Pode também favorecer o reconhecimento e o manejo de potencialidades ativas nas relações sociais e processos de poder na ótica do território, agregando uma diversidade de olhares sobre o mesmo para reconhecer a dinâmica socioterritorial e sua complexidade ${ }^{10}$.

Oportunizar a democratização das relações entre os diversos atores nos locais onde suas vidas acontecem e propiciar mudanças efetivas na percepção de bem-viver desses mesmos atores implica em apostar na construção de suas autonomias durante o próprio processo da ação pretendida. Segundo Oliveira11 "a noção de cidadania que deve orientar a tentativa de medir os processos e reservas de bem-estar e qualidade de vida se refere ao indivíduo autônomo, critico e reflexivo, muito longe, portanto, do indivíduo-massa”.

\section{Intersetorialidade(s) e vozes locais: seus valores, suas redes}

O plano local que pode apoiar a construção de autonomias, dar voz aos diferentes atores, fazer emergir novas soluções, aproximar-se da complexidade de soluções que ultrapassam as respostas setorializadas já conhecidas, precisa ir além das propostas que visam tão somente ações de apoio/desenvolvimento comunitário ou intervenções governamentais e profissionais planejadas em bloco, sem respeito às especificidades, só devidamente sinalizadas por quem as vive.
$\mathrm{Na}$ mesma linha de pensamento apresentada por Wimmer e Figueiredo ${ }^{12}$, constata-se que os planos locais capazes de modificar mentalidades em direção à autonomia contemplam ao mesmo tempo ações intersetoriais, relações humanas de apoio, relações profissionais e institucionais. Precisam dar destaque aos valores que fazem do espaço um território, dar visibilidade às relações de poder, particularmente às do poder simbólico, que caracteriza o pertencimento das pessoas a um determinado local.

$\mathrm{Na}$ verdade, os próprios planos/intervenções locais são expressões de relações que ocorrem simultaneamente: interpessoais, sociais e institucionais. Segundo Zúñiga ${ }^{13}$, é preciso estar atento e fazer a distinção entre os três mitos que mostram tendências perigosas, sempre presentes nesse tipo de ação: a não direcionalidade da ação em si, a ajuda-pela-ajuda e a ação planejada - onde a participação do ator local é somente a "validação faz-de-conta" do que já se havia decidido "em gabinete". Neste caso, apesar de tentar parecer uma ação comunicativa entre os planejadores/tomadores de decisão do nível central e os atores locais, o que ocorre é uma ação puramente instrumental, onde o nível local é utilizado para validar o que já estava planejado e decidido de antemão.

Dar voz ao ator local é reconhecer seus valores, o que faz com que essas pessoas se movam em direção a uma transformação ou mesmo à manutenção do "status quo". É saber o que motiva a formação de grupos, de redes, conhecer os desejos individual e coletivo das pessoas de um território. Reconhecer que as especificidades locais não só existem, mas que precisam ser efetivamente levadas em consideração, é fator facilitador essencial na resolução dos problemas complexos de cada território. Dessa forma, entende-se que um país multicultural como o Brasil deveria priorizar propostas regionalizadas e de caráter equitativo, de maneira a reduzir as iniquidades inter e intraterritorais.

A experiência brasileira no campo da saúde no processo de institucionalização e gestão do SUS, baseado na implementação de estratégias de territorialização das ações de atenção primária em saúde pode servir de exemplo para a construção de outras políticas e planos locais, como os de promoção da saúde. O reconhecimento das características socioeconômicas, ambientais, organizativas, programáticas, bem como as potencialidades e prioridades locais do território são considerados aspectos chave para a atuação sobre os determinantes da saúde e a implementação de estratégias de vigilância em saúde. 
A escuta dos atores e das redes sociais leva, necessariamente, a ações intersetoriais, uma vez que o campo da ação vivida não está setorializado, contrariamente ao que ocorre no campo da ação concebida ${ }^{5}$. Essa é a força da intersetorialidade: contemplar o mundo descompartimentalizado, como se dá na vida de cada um.

\section{Experiências brasileiras de promoção da saúde ancoradas no território}

O movimento das Redes de Cidades e Comunidades Saudáveis no Brasil vem se caracterizando, nos últimos anos, pelo fortalecimento de estratégias de promoção da saúde em contextos locais, por meio do desenvolvimento de ações intersetoriais sustentáveis no âmbito local, colocando a promoção da saúde como prioridade da agenda política. Nestas redes, a priorização de temas e a construção de alianças locais emergem de potencialidades e necessidades identificadas, consolidando-se como estratégica para melhorar as condições sociais, ambientais e sanitárias nos espaços onde as pessoas vivem, trabalham, estudam e se relacionam socialmente ${ }^{14}$.

Um levantamento realizado por Franco Netto e Fenner ${ }^{14}$, em 2011, destacava a experiência de cinco redes de Cidades/Municípios/Comunidades Saudáveis e Sustentáveis no Brasil, sendo elas a Rede de Municípios Potencialmente Saudáveis, Rede Pernambucana de Municípios Saudáveis, Rede de Ambientes Saudáveis de Curitiba, Rede de Comunidades Saudáveis no Rio de Janeiro e a Rede Brasileira de Habitação Saudável. Apesar de suas especificidades territoriais, similaridades podiam ser observadas no desenvolvimento destas redes e de suas ações locais, como o envolvimento de diversos atores político-institucionais, com distintas inserções, expressando suas especificidades simbólicas e culturais na construção de alianças por cidades saudáveis em municípios de pequeno, médio e grande porte.

Algumas destas experiências, ainda fortemente consolidadas, têm construído tecnologias e disseminado evidências de sua efetividade, como no caso da Rede Pernambucana de Municípios Saudáveis. A metodologia proposta para a mobilização local e a identificação de prioridades, conhecida como Método Bambu ${ }^{15}$, vem sendo construída e disseminada em diferentes contextos e pode ser apontada aqui como um exemplo importante de abordagem para apoiar a construção de planos locais de promoção da saúde.

\section{Uma abordagem de construção de um plano local de promoção da saúde}

Desde fins de 2003, a equipe técnica responsável pela atual Rede Pernambucana de Municípios Saudáveis buscava uma maneira de envolver efetivamente a população de cinco municípios do agreste pernambucano e construir propostas de promoção da saúde que fortalecessem a autonomia das pessoas, fossem participativas em todos os níveis, intersetoriais, e que colocassem ênfase nas potencialidades, mais que na escassez. Iniciando com uma pesquisa avaliativa e participativa de capitais social e humano, Yuasa et al. ${ }^{16}$ desenvolveram modelos que possibilitaram a construção do Método Bambu ${ }^{16}$.

Com etapas centradas em um processo participativo e reflexivo, por meio de continuadas avaliações, a própria construção metodológica passou a ser considerada como um processo de empoderamento local ${ }^{17}$. Desta forma, a reflexividade planejada e compartilhada pode ser considerada como um dos fatores de êxito do processo de construção do método, corroborando os pressupostos de Schön ${ }^{18}$ sobre a prática reflexiva.

O Método Bambu é uma ferramenta validada e potente para priorizar e planejar ações locais. De 2004/2005 até 2011 era utilizado somente no contexto nordestino, mas durante 2011 e 2012, foi utilizado por regiões administrativas do Distrito Federal dentro do curso para Territórios Saudáveis e Sustentáveis, numa parceria entre Universidade Federal de Pernambuco, Universidade de Brasília e Governo do Distrito Federal. Nessa ocasião, alguns novos instrumentos foram inseridos no método, como o quadro de relações entre atores. Os relatos e as evidências apontam para uma grande capacidade de promover consensos possíveis em torno da priorização de ações. O passo a passo para definição da ação priorizada permite a compreensão dos critérios e a pactuação em torno da ação mais factível e sobre a qual se tem mais governabilidade, como etapa preliminar para a execução de ações sobre as quais se tem menos governabilidade.

Idealizado como "um meio para impulsionar as potencialidades de uma comunidade, visando o seu fortalecimento e transformação"19, o Método Bambu foi também inspirado pelo modelo Sojo desenvolvido no Japão, pelo Sistema Soft de ação ${ }^{20}$, e o método APA (inquérito apreciativo para construção de capacidades humanas) ${ }^{21}$, todos alicerçados em abordagens afirmativas que valorizam o potencial individual e coletivo das populações e transformações subjetivas como 
mecanismos para mudanças sociais e enfrentamento dos determinantes da saúde.

O Método Bambu parte do pressuposto de que sempre há experiências positivas a relatar. A partir delas, busca extrair potencialidades individuais e coletivas, muitas vezes não percebidas pela população interessada. Faz-se na verdade uma consulta de "quereres" e um mapeamento de prioridades de forma participativa. De acordo com Pessoa et al..$^{22}$, esse tipo de mapeamento desvela percepções, sedimenta conhecimentos, propicia redescoberta de territórios e facilita a realização de planos de ação.

A sequência apresentada abaixo descreve o passo a passo do método.

\section{Método Bambu: passos metodológicos}

1. Um quadro de correlação entre experiências positivas, aprendizado e potencialidades é montado coletivamente. As potencialidades dizem respeito às experiências positivas vividas pela população e ao aprendizado retirado destas experiências relativas à qualidade de vida, geração de renda, reforço de laços comunitários, conquistas locais, solidariedade, respeito, justiça social, participação, cooperação. Deve reunir pessoas-chave do território para extrair as respostas;

2. Logo em seguida propõe-se a descrição dos desejos para a coletividade local e um segundo quadro é esboçado;

3. Esses desejos devem ser sintetizados numa frase;

4. Com base nas potencialidades e desejos, faz-se uma lista do que se quer, partindo do que se tem concretamente no momento, ou seja, as ações a serem executadas (Quadro 1).
5. Para escalonar prioridades e selecionar ações, um mapa é construído utilizando dois critérios: interesse e tempo. Usam-se bolas representando os interesses (grande - interesse da maioria do grupo; média - interesse de alguns; pequena - pouco interesse). O tempo é representado por cores (p.ex.: verde $=$ pouco tempo e rosa $=$ muito tempo) (Figura 1).

6. Identificação dos atores envolvidos. Deve-se listar todos os possíveis atores sociais envolvidos em cada ação, até os institucionais (Quadro 2).

7. Elabora-se o Mapa de Prioridades - análise das prioridades e seleção dos objetivos mais simples. Utilizando-se as bolas com as ações definidas no quadro anterior, constrói-se, pouco a pouco, um novo quadro para dar visibilidade e promover tomada de consciência na escolha das primeiras ações a serem executadas. Identifica-se com um quadrado central significando onde se tem maior governabilidade de execução (depen-

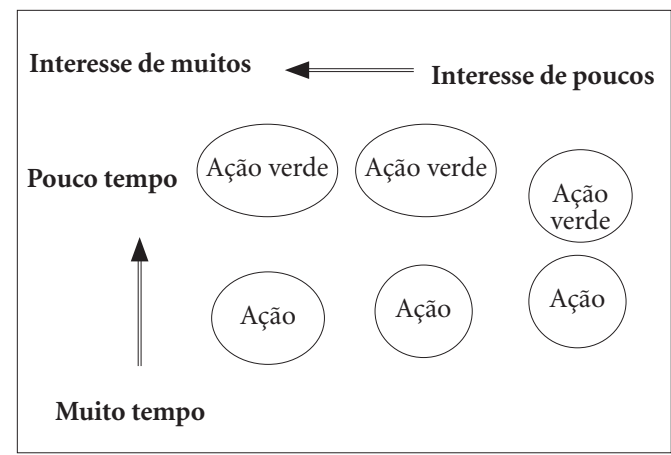

Figura 1. Seleção de ações.

Quadro 1. Grau de governabilidade das ações e desejos.

\begin{tabular}{|c|c|c|}
\hline Ações/desejos & $\begin{array}{c}\text { Evidências da necessidade da ação/desejo } \\
\text { (podem listar dados secundários, relatos, } \\
\text { resultados de vivências e/ou observações) }\end{array}$ & $\begin{array}{c}\text { Grau de governabilidade para resolução: } \\
\text { 1- nenhuma; 2- influência indireta; } \\
\text { 3- total }\end{array}$ \\
\hline & & \\
\hline
\end{tabular}

Quadro 2. Identificação dos atores.

\begin{tabular}{|l|c|c|c|}
\hline Ator social & $\begin{array}{c}\text { Nível de ação (local, comunitária, municipal, } \\
\text { estadual, regional, federal) }\end{array}$ & $\begin{array}{c}\text { Aposta/interesse } \\
\text { em jogo }\end{array}$ & $\begin{array}{c}\text { Saber/fazer que traz } \\
\text { para o coletivo }\end{array}$ \\
\hline & & & \\
\hline
\end{tabular}


de menos de outros setores ou de terceiros). No limite do quadrado, colocam-se as bolas com as ações que precisam de algumas negociações com outras pessoas, setores ou instituições (governabilidade mediana). Fora do quadrado, ficam as bolas com as ações que possuem alto grau de dependência de terceiros para a sua execução (pouca governabilidade). Seleciona $(\mathrm{m})$-se $\mathrm{a}(\mathrm{s})$ ação(ões) sobre a(s) qual(is) se possui maior governabilidade, de interesse a um maior número de pessoas e que possa ser executada mais rápido para incentivar o planejamento de ações mais complexas posteriormente. A elaboração desse mapa é capaz de promover consenso entre grupos heterogêneos com alto grau de controvérsia na escolha da ação.

8. Identificam-se as relações entre os atores para desenvolver estratégias de execução das ações priorizadas (Quadro 3).

9. Desenha-se um mapa, onde cada ator social será representado por tamanho diferente de acordo com o grau de importância na ação, segundo análise do grupo. Os atores que possuem interação natural ou atuação similar devem ser representados da mesma cor. Identificar aqueles cuja "ligação" pode gerar conflitos (existência de posições ou ações incompatíveis/excludentes) ou controvérsias (existência de polêmicas, disputas intelectuais, dúvidas, contestações) na ação.

10. Elabora-se um quadro final (plano) com ação/atividade selecionada (o quê), responsável (quem), parcerias necessárias (quem), estratégia (como), prazo (quando).

\section{Considerações finais}

Ao se discutir questões afeitas à cidadania, aos direitos humanos e ao direito à saúde deve-se apoiar reflexões coletivas e buscar alternativas políticas e programáticas territorializadas, social- mente enraizadas e articuladas intra e extrassetorialmente ${ }^{23}$. Dessa forma, o desenvolvimento de planos regionais ou locais deve se impor como a via de eleição para ações de promoção da saúde, uma vez que incentiva a autonomia individual e o empoderamento, desperta os atores locais, prioriza ações que destacam especificidades conhecidas por todos, dá visibilidade aos contextos sociopolíticos e estimula soluções criativas e factíveis para os problemas locais. Reduzir iniquidades - princípio fundamental da promoção da saúde - significa conhecer, olhar, ver e ouvir as diferenças, semelhanças e especificidades entre as pessoas, suas condições sociais e econômicas e seus ambientes e espaços vividos e concebidos, buscando alternativas para a resolução de seus problemas complexos condizentes com o seu contexto, história e pertencimentos. Há de se incentivar a realização de planejamentos vinculados aos territórios e aos desejos dos atores que ali vivem. O método apresentado como modelo tem propiciado a realização de planejamentos com essas características e tem se mostrado efetivo para esse fim.

\section{Colaboradores}

ST Moysés e R Franco de Sá colaboraram em todas as fases de elaboração do artigo

Quadro 3. Relações entre atores.

\begin{tabular}{|c|c|c|c|c|}
\hline $\begin{array}{c}\text { Ator } \\
\text { social }\end{array}$ & $\begin{array}{c}\text { Papel } \\
\text { na ação }\end{array}$ & $\begin{array}{c}\text { Grau de importância: } \\
\text { 1-sem importância, 2- pouco importante, } \\
\text { 3- importante, 4- muito importante, } \\
\text { 5-imprescindível }\end{array}$ & $\begin{array}{c}\text { Interage } \\
\text { com... }\end{array}$ & $\begin{array}{c}\text { Tipo de interação: } \\
\text { Parceria(Pa) } \\
\text { Controvérsia }(\mathrm{Ct}), \\
\text { Conflito }(\mathrm{Co})\end{array}$ \\
\hline & & & & \\
\hline
\end{tabular}




\section{Referências}

1. World Health Organization (WHO). Health promotion evaluation: recommendations to policymakers. Copenhagen: European Working Group on Health Evaluation; 1998.

2. Poland B, Frohlich K, Cargo M. Context as a fundamental dimension of health promotion program evaluation. In: Potvin L, Macqueen D. editors. Health Promotion evaluation practices in the Americas. Washington: Springer; 2008. p. 299-318.

3. World Health Organization (WHO). Adelaide Recommendations on Healthy Public Policy. Second International Conference on Health Promotion, Adelaide, South Australia, 5-9 April 1988.

4. Gadelha CAG, Machado CV, Lima LD, Baptista TWF. Saúde e territorialização na perspective do desenvolvimento.Cien Saude Colet 2011; 16(6):3003-3016.

5. Lefebvre H. The production of space. Oxford, Cambridge: Blackwell Publishers; 1991.

6. Haesbaert R. O mito da desterritorialização: do "fim dos territórios” à multiterritorialidade. Rio de Janeiro: Bertrand Brasil; 2007.

7. Raffestin C. Por uma geografia do poder. São Paulo: Ática; 1993.

8. Santos M. A natureza do espaço: razão e emoção, técnica e tempo. São Paulo: Hucitec; 1996.

9. Araújo TB. Políticas públicas e promoção do desenvolvimento em bases territoriais. Apresentação no II Fórum Internacional de Desenvolvimento Territorial: articulação de políticas públicas e atores sociais. Salvador; Nov. 2007.

10. Andrade FS. Considerações sobre a perspectiva territorial da política pública de assistência social no Brasil. Revista Urutágua 2009; 18:127-132.

11. Oliveira F. Aproximações ao enigma: que quer dizer desenvolvimento local? In: Spink P, Caccia Brava S, Paulics V, coordenadores. Novos contornos da gestão local: conceitos em construção. São Paulo: Instituto Pólis; 2002. p. 11-32.

12. Wimmer GF, Figueiredo GO. Ação coletiva para qualidade de vida: autonomia, transdisciplinaridade e intersetorialidade. Cien Saude Colet 2006; 11(1):145-154.

13. Zúñiga R. La construction des autonomies dans l'intervention - intentions et institutionalisations. In: Nelisse MC, editeur. L'intervention: les savoirs en action. Sherbrokee: Éditions GGC Université de Sherbrooke; 1997. p. 77-100.

14. Franco Netto G, Fenner R, organizadores. Levantamento das iniciativas e redes brasileiras de comunidades, municípios e cidades saudáveis e sustentáveis: modelos, estratégias, resultados e parceiros. No prelo; 2011.
15. Franco de Sá R, Araújo JA, Freire MSM, Senna Salles, R, Chuma J, Royama H, Yuasa M, Yamamoto S, Menezes Filho A. Manual do método Bambu - construindo municípios saudáveis. Recife: Editora Universitária UFPE; 2007.

16. Yuasa M, Franco de Sá R, Pincovsky S, Shimanouchi N. Emergence Model of social and human capital and its application to the Healthy Municipalities project in Northeast Brazil. Health Promot Int 2007; 22(4):292298.

17. Franco de Sá R, Moysés ST. O Processo Avaliativo em Promoção da Saúde como Estratégia de Empoderamento e de Desenvolvimento de Capacidades. Boletim Técnico do Senac: a revista da educação profissional 2009; 35(2):29-36.

18. Schön DA. Le praticien réflexif: à la recherche du savoir caché dans l'agir professionnel. Québec: Les Éditions Logiques; 1994.

19. Menezes Filho A, Franco de Sá R, Freire S. Método Bambu. In: Franco de Sá R, Yuasa M, Viana VP. Organizadores. Municípios Saudáveis no Nordeste do Brasil Conceitos, Metodologia e Relações Institucionais. Recife: Editora Universitária UFPE; 2006. p.53.

20. Checkland, P, Scholes J. Soft Systems Methodology in Action. Chichester, New York, Weuinheim, Brisbane, Singapore, Toronto: Jon Wiley and Sons Ltd; 2000.

21. Chapagain CP. Appreciative Inquiry for Building $\mathrm{Hu}$ man Capacities: An Innovative Approach for the New Millennium. Kathmandu: Plan-International; 2005.

22. Pessoa VM, Rigotto RM, Carneiro FF, Teixeira ACA. Saúde e métodos de territorialização na atenção primária à saúde. Cien Saude Colet 2013; 18(8):2253-2262.

23. Ribeiro PT. Direito à saúde: integridade, diversidade e territorialidade. Cien Saude Colet 2007; 12(6):15251532.

Artigo apresentado em 02/08/2014

Aprovado em 11/08/2014

Versão final apresentada em 12/08/2014 
